\title{
The Relevance of Reserved Officer Training Unit in College Students Committee on the Perspective of Civilian Students
}

\author{
Muhammad Hariz Asraf ${ }^{1}$ Mohd Noor Azli Ali Khan ${ }^{2 *}$ Mohd Syahlan Mohd Syukri ${ }^{3}$ \\ Siti Nur Hayati Hamsan ${ }^{4}$
}

\author{
${ }^{1}$ Department of Biosciences, Faculty of Science, Universiti Teknologi Malaysia, 81310 UTM Johor Bahru, Johor, \\ Malaysia \\ ${ }^{2}$ Azman Hashim International Business School, Universiti Teknologi Malaysia, 81310 UTM Johor Bahru, Johor, \\ Malaysia \\ ${ }^{3}$ School of Chemical and Energy Engineering, Faculty of Engineering, Universiti Teknologi Malaysia, 81310 UTM \\ Johor Bahru, Johor, Malaysia \\ ${ }^{4}$ School of Biomedical Engineering \& Health Science, Faculty of Engineering, Universiti Teknologi Malaysia, 81310 \\ UTM Johor Bahru, Johor, Malaysia \\ *Corresponding author. Email: m-nazli@utm.my
}

\begin{abstract}
Reserved Officer Training Unit (ROTU) is an entity exclusive only to certain public universities including Universiti Teknologi Malaysia (UTM). This entity is a standalone organisation supported by the respective universities through Ministry of Defence Malaysia and supported by Ministry of Education Malaysia. Consisted of undergraduate students, these students undergone a series of training to enable them to be commissioned as officers in the national armed force. Since the training of ROTU is compulsory and considering its timeframe, ROTU students are believed to face time constraints and packed schedules which limit their commitment in any other organisations despite their volunteerism. Therefore, this study was driven on the perspective of non-ROTU students on the relevance of ROTU students in students' representative committee or Jawatankuasa Kolej Mahasiswa (JKM) of Tun Dr. Ismail College (KTDI) specifically. The method used is through questionnaires by integrating answers from students' session 2018/2019 and below who committed in JKM previously. A total of 39 students who actively joined JKM and recognized as civilians was chosen as the respondents. A set of questionnaires was handed out to the respective respondents on the theme of relevancy of ROTU as well as its necessity to appoint them as one of the JKM. The study found out that ROTU is such a necessary presence in JKM since it is considered as one of the college's identity. KTDI is the only college that houses ROTU students. Hence, it is important to preserve such symbol. Other than that, majority is in the opinion that everyone should be given equal privilege and no compulsion is placed for the appointment of JKM from ROTU. The study concluded that ROTU still maintains its relevancy in JKM of KTDI.

Keywords: reserved officer training unit, civilian, volunteerism, relevance, identity

\section{INTRODUCTION}

Volunteerism is one of the characteristics encouraged by the Ministry of Education besides instilling the love, happiness, and mutual respect as stated by Maszlee Malik (2018) in his vision towards a positive and better campus life experience [1]. Studying is not the only option to graduate with flying colours, but the time, resources and energy spent through joining various campus activities and programmes will put the students, one rank higher above others. The spirit of volunteerism defines as the practice of providing time and relevant skills for the benefit of other people excluding

financial benefit goal. Furthermore, it is a skill unobtainable in class but out in the field. The act of volunteerism usually involves the community surrounding the campus or within the campus itself. Since the meaning is very broad, it is applicable regardless of time and place.

In the context of this paper, Malaysian graduate students usually spend four years or less in their bachelor's degree study period. Therefore, it is an impeccable opportunity to indulge a self-learning experience by joining clubs or associations to extort the spirit of volunteerism. Generally, each campus including college, University College, private or public universities offer a wide selection of joinable associations during the first week of new intake student's
\end{abstract}


registration. This has been a global practice in United States of America (USA), by exploiting a mandatory volunteer work as a requirement for graduating which is a good way of enforcement to the students [2].

Specifically, in Universiti Teknologi Malaysia (UTM), there exist a special entity associated with the Ministry of Defence Malaysia namely Reserved Officer Training Unit (ROTU). This is a standalone entity exclusive to only certain public universities including Universiti Teknologi MARA (UiTM), Universiti Pertahanan Nasional Malaysia (UPNM), Universiti Malaya (UM), and many more. Consisted of undergraduate students, these students undergone a series of training to enable them to be commissioned as officers in the national armed force. Therefore, indirectly it is an act of volunteerism towards serving both the university and for the latter, country. In UTM, each residential college has its own student representative committee known as Jawatankuasa Kolej Mahasiswa (JKM). This JKM is responsible to assist the college in the aspects of student's development, volunteerism, welfare and providing platform for students to join interesting events and programs in a college. Kolej Tun Dr. Ismail (KTDI), one of the residential colleges with 1613 students of 2018/2019 session housing these JKM recently faces a certain challenge of assessing the performance of ROTU students in JKM. Since ROTU students have packed schedules to begin with, the additional portfolio as JKM might hinder their performance as a whole. Then, this has been a challenge for the JKM to keep up with their performances. It has been found out that the ROTU students involved in this committee have to, without any choice, balance and smartly organize their daily activities. As a student, priority and preferences differs from one person to another. Thus, one might enjoy doing voluntary works while others do not [3]. On the other hand, it has always been a question on the importance of ROTU student's presence in JKM of the college.

Therefore, the objective of this study encompasses the relevance of ROTU students in JKM especially in KTDI on the perspective of non-ROTU students. The civilian perspective is an important indicator in this research as it will put a baseline for the management in the appointment of ROTU students in JKM. Additionally, the finding of this research is important to elaborate and evaluate the suitability of a ROTU student to be appointed as one of the JKM members.

\section{LITERATURE REVIEW}

Volunteerism is a conceptual term in regards to a person's act. It is a very popular term across the globe and welldefined in all organizations and institutions from schools to workplaces. According to Synder and Omoto (2008), there are six characteristic features defining volunteerism. Firstly, the act must be on one's free will with no obligation or coercion. Secondly, this action must involve some discussions or decision making and does not emerge from impromptu assistance act reflexive act of helping. Thirdly, it must be done over a period of time, and sometimes extended over weeks or months in regards to particular objective. Fourthly, the act of volunteerism should be done without the expectation of reward or punishment, therefore activities that in the end eligible to be receiving money or to avoid punishment are not considered. Fifthly, the voluntary service should not be forced out towards a community, however must be done as been sought and accepted by the recipients. Lastly, it must be performed on behalf of others on a certain platform including agencies or organizations. Thus, distinction is made between informal and formal helping [4].

The conceptual meaning of volunteerism in an angle of view certainly put a logical term to define a voluntary work. It is always associated with an entity, organization or agency with the exclusion of altruism. In the meantime, not all voluntary works are easily accessible and free of obstacles [5]. Therefore, certain points of view are considered including its accessibilities, awareness level, prejudice, and lacking of support.

Positively, volunteering in an established organization will provide an easier platform to get access for voluntary works. This enables the particular organization to comprehensively discuss and make decision on what, when, where, why and how questions. A previous study was conducted on the volunteerism after-school time which can be related to this study on the volunteering for Science, Technology, Engineering and Mathematics (STEM) teaching [6]. It stated that involvement in community programs can broaden the horizon and experience of the students, while encouraging social responsibility.

The social interaction inter-personally is important to drive the vision of the particular organization towards its goals. On the study carried out on the inter-personal ties involving school or university in South Korea stated that, this tie is incompatible to achieve research collaboration [7]. In contrast, inter-personal ties in school or university may be indirectly assists the organization through procurement of relevant knowledge between both entities. In the end, this tie could be an instrument to create a bond for positive outcome in university-industry collaboration. In the case of this study, the different background of ROTU and civilian in JKM may be good inter-personal and inter-organizational ties in order to create a more outstanding achievement and programmes through exchange of ideas and knowledge.

Students involved in additional co-curricular activities are likely to be more motivated and have higher skills. Previous study by Rahmat et al. (2018) has assessed the overall affective domain of ROTU students after the training in the respective universities. The domains assessed include communication, critical thinking and problem solving, continuous learning and information management, teamwork skills, entrepreneurship skills, leadership skills, and ethics, moral and professionalism. It was found out that the students only achieved good and moderate level of domains in average [8]. Further studies were also conducted 
to assess the co-curricular Assessment Index (IPKo) of the cadets after three years of training on the effectiveness of cognitive and psychomotor domains achievement [9,10]. Complementarily, an additional finding has contemplated the psychological readiness of the three collegiate armed uniforms including Police Undergraduate Voluntary Corp (SUKSIS), ROTU: Air Force, and Territorial Army Regiment (WATANIAH). The finding concludes that different armed units promote different psychological environment and roles. Therefore, it is important to evaluate these students during their trainings and outside their training regimes [11].

\section{METHODOLOGY}

This study used quantitative research method. A total of 39 students who were actively joined the Students Representatives Committee (JKM) session 2018/2019 and below previously and recognized as civilians (non-ROTU) were chosen as the respondents in this study. The data was collected using online questionnaire and distributed using Google Forms to determine the relevance of ROTU in JKM of KTDI, specifically. The questionnaire was divided into three sections which were Section A containing data of the respondent's personal information, Section B containing questions regarding on the correlation between non-ROTU and ROTU JKM and Section C containing open-ended queries regarding the respondent's opinion on the same theme. The data from the questionnaire were obtained and analysed using descriptive methods. All the data were presented in percentage forms and analysed to determine the relevancy of ROTU in JKM based on non-ROTU perspectives.

\section{FINDINGS}

Section A of this study comprises the assessment of the gender and academic achievement of the respondents which is important to be included. This response is incorporated to justify the respondent's ability to make wise judgment and decision.

Fig. 1 (a) shows the gender of the respondents, there were more female respondents than male respondent which are $66 \%$ of the respondents while $34 \%$ were male respondents. In order to study the perspectives of the respondent, gender was one of the significant factors that should be considered. Besides, this study also shows that most of the respondents have average CGPA 3.00-3.69 which contribute about 85\% of the data and $9 \%$ of them have average CGPA 3.70-4.00 (Fig. 1 (b)). This shows that most of the students who involved in JKM have good curricular records throughout their study periods. These respondents were carefully chosen to ensure unbiased and honest responds for this study.
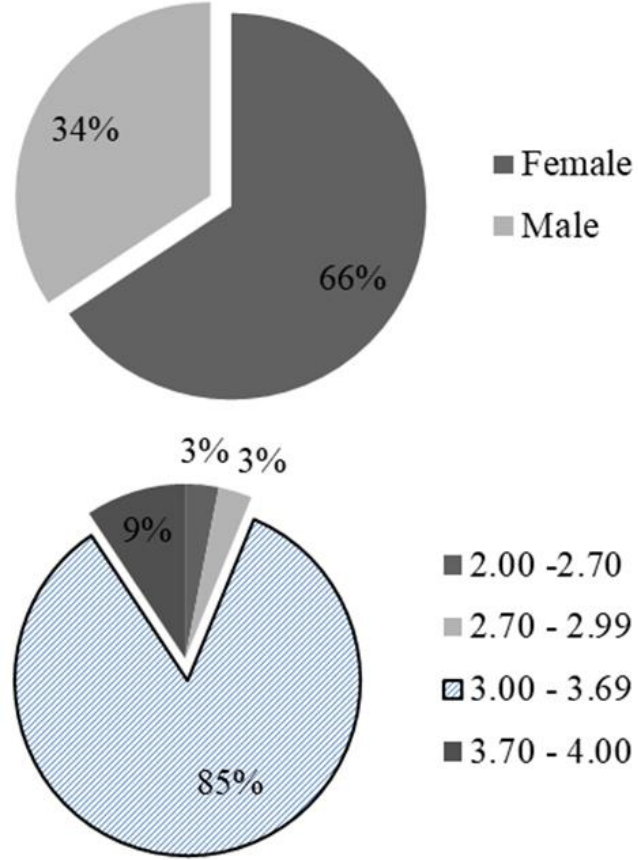

Figure 1 The distribution of the (a) gender and (b) academic achievement, cumulative grade point average (CGPA) of the 39 total respondents in this study

Section B comprises the analysed questionnaire distributed to the respondents regarding the relevance of ROTU in JKM. It is based on the opinions of the respondents about the statements given. The data is tabulated and presented in percentage $(\%)$.

Table 1 shows the percentage of the respondents who participated in the study. Majority of the respondents disagree that there is a social gap between ROTU JKM with JKM committee with a total of $46 \%$ while the least percentage of respondent is $26 \%$ who basically agree. The highest percentage of respondent saying that JKM ROTU and JKM committee that have good cooperation during the programme is $44 \%$ and otherwise, those who have thought cooperation is barely enough is at $33 \%$. Majority is on the same boat with the opinion that it is easier to obtain working force when there is a presence of ROTU during any programmes with $71 \%$ in total. It is deduced that the committee in JKM still maintain their social interactions by keeping them professional as necessary. Therefore, through this quite strong bond, any assistance from the ROTU side is welcomed as needed. In addition to that, statement 5 likely to relate with statement 3 if the higher committee position is held by the ROTU, assistance from ROTU is easily accessible through them by "chain of command". Chain of command basically relates to the ROTU organization which the lower ranking students have to abide the command given by their higher-ranking seniors or officers. As this has been put as their custom, and out of respect, the cadets have to agree upon the commands or tasks given by their authorities. 
Table 1 Correlation of both ROTU and civilians in JKM as part of the same committee in percentages (\%) for 39 respondents

\begin{tabular}{|c|c|c|c|c|c|c|}
\hline Statements & 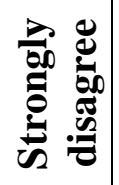 & 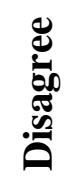 & 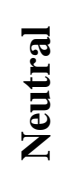 & 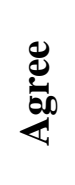 & 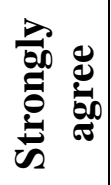 & हే \\
\hline $\begin{array}{l}\text { (1) There is social gap between JKM ROTU } \\
\text { with JKM }\end{array}$ & 28 & 18 & 28 & 16 & 10 & \multirow{6}{*}{$\begin{array}{c}39 \\
(100 \%)\end{array}$} \\
\hline $\begin{array}{l}\text { (2) JKM ROTU and JKM committee only } \\
\text { have good cooperation during the } \\
\text { programme }\end{array}$ & 23 & 21 & 23 & 23 & 10 & \\
\hline $\begin{array}{l}\text { (3) It is easy to have manpower in order to } \\
\text { run the programme with the involvement of } \\
\text { both JKM ROTU and JKM }\end{array}$ & 0 & 3 & 26 & 38 & 33 & \\
\hline $\begin{array}{l}\text { (4) JKM ROTU required to attend JKM } \\
\text { programme even though it is overlapping } \\
\text { with their training programme }\end{array}$ & 13 & 10 & 44 & 18 & 15 & \\
\hline $\begin{array}{l}\text { (5) JKM ROTU necessarily to be in higher } \\
\text { council of the committee }\end{array}$ & 2 & 3 & 31 & 23 & 41 & \\
\hline $\begin{array}{l}\text { (6) The absence of JKM ROTU in JKM- } \\
\text { related programme can be replaced by other } \\
\text { JKM members }\end{array}$ & 5 & 5 & 28 & 41 & 21 & \\
\hline
\end{tabular}

On the other hand, the respondents are neutral with $44 \%$ when it comes to put a priority whether to attend JKM programmes or ROTU training. However, in the absence of ROTU during any JKM programmes, the respond (6) is quite related to the previous respond (4) which state that the ROTU may be replaced by other JKM members with the highest majority at $62 \%$. Therefore, the neutral respond on statement 4 may be flexible due to the replacement that can be made before or during the programme if ROTU JKM is unavailable. So, this strongly shows the tolerance given within the JKM itself to help each other out professionally. Conclusively, most of the respondents agreed that JKM ROTU and civilians still maintain their professional networking and relationship in the organization with strong sense of tolerance, responsibility and cooperation. It is also found out that they acknowledge the positions and privilege bestowed upon them and put these to a good use.

The last part of this study is the section C (Fig. 2) which considers the opinion of the students in open-ended answer. The data discussed in this part consists of strongly related queries to the previous section $B$ with the exclusion of preliminary questions.

In order to relate the findings in Fig. 2 with previous sections, several data on the open-ended questions have been considered to establish acceptable correlation and significance. Since the establishment of JKM in KTDI, ROTU has been a part of the committee members. The appointment recently follows a quite strict ratio of $1: 1$ which consist of both ROTU and civilians. According to Fig. 2 (a), majority with $61 \%$ is comfortable with the recent regulation of $1: 1$ appointment ratio. This is because majority concerns on the value of fairness, equal opportunity for all and there would be no such bias. Equality of opportunity emerges with substantially popular support and being regards as a distributive justice which does not compromise any lacking in a person [12]. This study proposed that an act with distributive justice always be returned with popular supports from majority. Hence, this $1: 1$ rule implemented is the key to promote equality and equity for all students. 


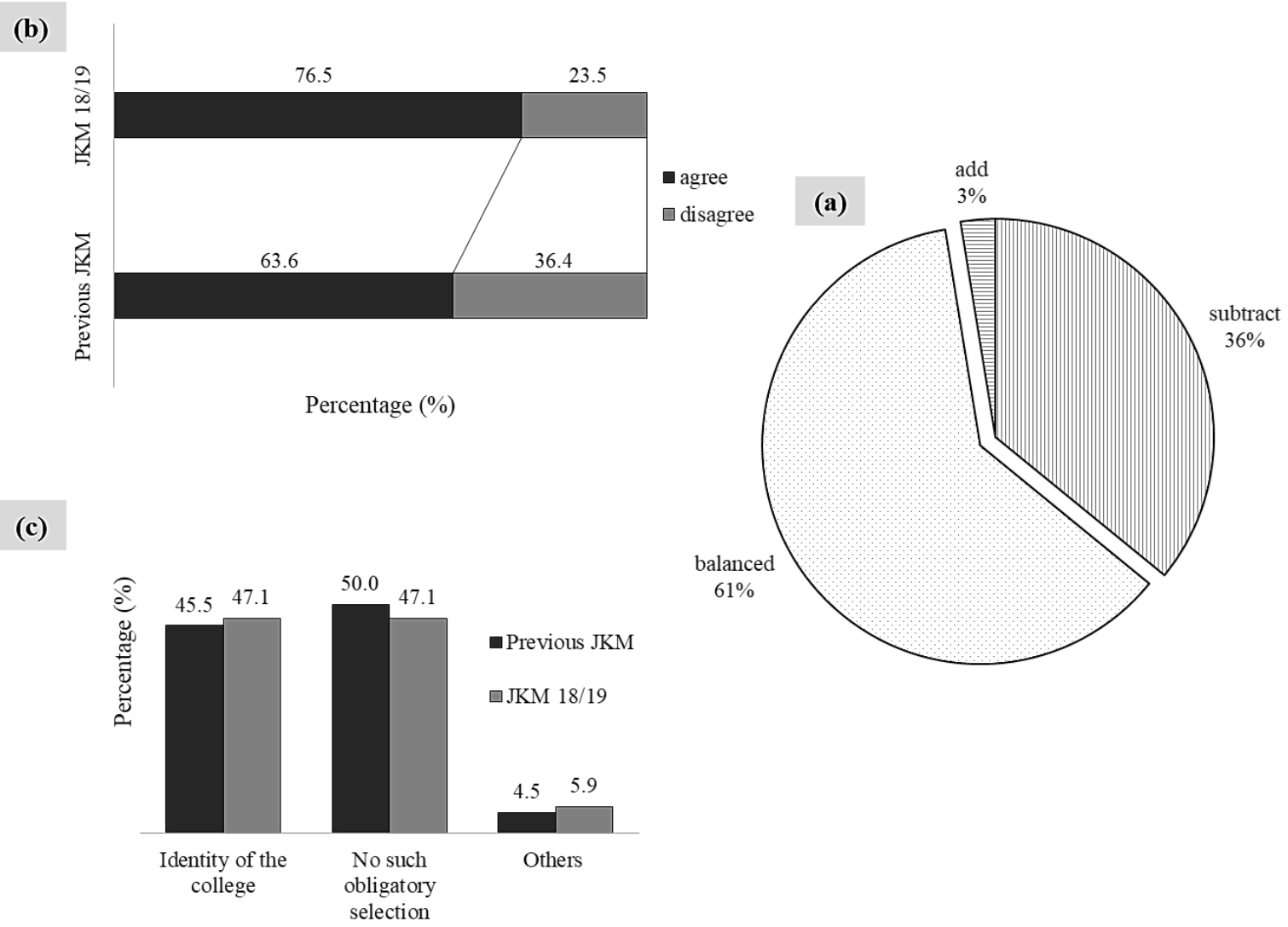

Figure 2 The quantitative analyses of the open-ended answers related to the study from 39 respondents. This part consists of (a) the opinion on 1:1 ratio between ROTU and civilian in JKM, (b) the privilege of presidential position given to ROTU, and (c) the ultimate feedback on the relevancy of ROTU as a part of JKM members

On the other hand, Fig. 2 (b) and (c) are related and can be linked to (a) as well. The presidential position is, by custom, given to ROTU student through the selection from a council of fellows in the institution. Since KTDI is the only residential college with ROTU students, this privilege is given to them but with a strict selection depending student's commitment, leadership, influence, personality and academic achievement. According to the finding, majority agrees on the privilege given to the ROTU with 76.5 and $63.6 \%$. Mostly concern that it is the identity of the college, while ensuring the welfare of ROTU students is not neglected. Privilege on this point of view reflects the decision making by the members to be presented to higher bodies in the institution. As stated by Binderkrantz (2005), a group with privileges has higher activities targeting the decision makers. The trend shows that privileged groups have the platform for their voices to be heard directly by the higher board members in the institution [13]. Lastly, the assessment on the ultimate question in regards to the relevancy of ROTU to be in JKM has been presented in Fig. 2 (c). There is an almost equal correlation of both answers which can be connected as such, "the appointment of ROTU as part of the committee is to be upheld and protected as the identity of the college and should be done without force or obligatory selection". Identity is important to dictates the question of "who are we?" or "what do we want to be?" as stated in a book entitled Organizational Identity: A Reader [14]. Therefore, identity can be empirically presented as it does satisfy the following criteria of original essence of the body, has distinctiveness, and preservation over time. Both findings agree on the perseverance of the identity of the college.

\section{CONCLUSION}

Based on the findings of all related questionnaire, the objectives of this study have been fulfilled which JKM ROTU is still relevant in JKM KTDI. The respondents who live in KTDI have a strong affinity towards the residential college particularly. This is because only KTDI houses ROTU students and this will may be forever an identity to this college. Majority of the respondents agree to uphold the relevance of ROTU students to be in the committee of JKM although minority has casts disagreement on the involvement of ROTU. This could be deduced as a social gap that pushes both of the ROTU and non-ROTU students apart. The data also depicts the disagreement on the obligatory involvement of ROTU students in JKM, but should be based on sole volunteerism spirit. Besides that, all students have to be given an equal opportunity to put their volunteering skills into realization. This implicates that for 
future selection of committee in JKM, ROTU students will be more inspired and realize that the appointment as JKM has become a part of their successful soft skill development and accepted by the college itself. Furthermore, they should not point out their worries over the social gap in the organization but it is their job to improvise and learn.

Also, this study is only limited to a certain respondent in UTM only but not the whole Malaysian academic institution. However, this study will put a benchmark on the relevance of ROTU students in JKM for an in-depth assessment in the future. Additionally, more parameters should be considered for other academic institutions including existing workload, preferences, ethnicity, geographical assessment, parenting history and more. Thus, a comprehensive result may be presented to fill in all the research gaps found in this study.

\section{ACKNOWLEDGMENT}

We would like to thank Kolej Tun Dr. Ismail (KTDI) and Universiti Teknologi Malaysia (UTM) for the financial support.

\section{REFERENCES}

[1]T. Arumugam, Happiness, love and mutual respect, key to positive learning environment - Maszlee, New Straits Time. (2018).

https://www.nst.com.my/news/nation/2018/06/376280/ happiness-love-and-mutual-respect-key-positivelearning-environment.

[2]J. Wilson, Volunteerism Research: A Review Essay, Nonprofit Volunt. Sect. Q. 41 (2012) 176-212. DOI: https://doi.org/10.1177/0899764011434558.

[3]A.L. Denton, Students Perception of Required Volunteerism, Morehead State University, 2019.

[4]M. Snyder, A.M. Omoto, Volunteerism: Social issues perspectives and social policy implications, Soc. Issues Policy Rev. 2 (2008) 1-36. DOI: https://doi.org/10.1111/j.1751-2409.2008.00009.x.

[5]G. Yanay-Ventura, "Nothing About Us Without Us" in Volunteerism Too: Volunteering Among People with Disabilities, Voluntas. 30 (2019) 147-163. DOI: https://doi.org/10.1007/s11266-018-0026-7.

[6]B.N. Wagner, STEM Ready: Inspiring and Preparing Undergraduate Students for Successful Volunteerism in After-School STEM Programming with Marginalized Youth, Merrimack College, 2019. https://scholarworks.merrimack.edu/soe_student_ce/25/
[7]M. Hemmert, The relevance of inter-personal ties and inter-organizational tie strength for outcomes of research collaborations in South Korea, Asia Pacific J. Manag. 36 (2019) 373-393. DOI: https://doi.org/10.1007/s10490-017-9556-6.

[8]A. Rahmat, M.I. Shahril, N. Salimin, M.A.R. Ahmad, A.M. Nadzalan, The Assessment of Affective Domain among PALAPES in UPSI, Int. J. Acad. Res. Bus. Soc. Sci. 8 (2018) 293-299. DOI: https://doi.org/10.6007/ijarbss/v8-i1/3808.

[9]A. Rahmat, M.I. Shahril, N. Salimin, M.A.R. Ahmad, G. Elumalai, R. Johan, A.M. Nadzalan, Cognitive Domain Achievement Level among Reserve Officers Training Team (PALAPES), Int. J. Acad. Res. Bus. Soc. Sci. 7 (2017) 198-203. DOI: https://doi.org/10.6007/ijarbss/v7-i11/3451.

[10]A. Rahmat, M.I. Shahril, N. Salimin, M.A.R. Ahmad, A.M. Nadzalan, The Assessment of Psychomotor Domain Among Reserve Officers, J. Fundam. Appl. Sci. 9 (2017) 1389-1397. DOI: http://dx.doi.org/10.4314/jfas.v9i6s.103

[11]N.A. Kosni, M.R. Abdullah, S.N.W. Azman, A.B.H.M. Maliki, R.M. Musa, A. Adnan, S.M. MatRasid, H. Juahir, Comparison of Psychological Readiness Factors among the Collegiate Armed Uniform, Int. J. Acad. Res. Bus. Soc. Sci. 8 (2018) 97115. DOI: https://doi.org/10.6007/ijarbss/v8-i2/3859.

[12]J.E. Roemer, A. Trannoy, Equality of Opportunity, Handb. Income Distrib. 2 (2015) 217-300. DOI: https://doi.org/10.1016/B978-0-444-59428-0.00005-9.

[13]A. Binderkrantz, Interest Group Strategies: Navigating between Privileged Access and Strategies of Pressure, Polit. Stud. 53 (2005) 694-715. DOI: https://doi.org/10.1111/j.1467-9248.2005.00552.x.

[14]M.J. Hatch, M. Schultz, Organizational Identity: A Reader, illustrate, Oxford University Press, Oxford, 2004. https://books.google.com.my/books?id=12R7DwAAQB AJ. 